\title{
Microscopic Evaluation of Fungal Cleaning Protocols for Aircraft Coatings
}

\author{
Treva T. Brown ${ }^{1 *}$, Jason S. Lee ${ }^{1}$ \\ 1. Naval Research Laboratory, Stennis Space Center, MS, USA \\ * Corresponding author: Treva.Brown@nrlssc.navy.mil
}

Navy and Marine Corps aircraft operate around the world most frequently in hot, humid environments. Organic coating systems are used to protect aluminum aircraft skins and structural members from corrosion. In interior regions of the aircraft where sunlight/ultraviolet light cannot penetrate and, exacerbated by the heat and humidity, mold and mildew (fungal) spores may attach and proliferate leading to microbiologically influenced corrosion (MIC) [1]. Corrosion preventive compounds (CPC's) and mildew inhibitors have been previously evaluated in prevention of corrosion and fungal growth, respectively [2]. Hydraulic fluid (HF) is also present on most aircraft surfaces through unintentional deposition as a part of the normal operation of the aircraft. Fungi have been shown to be capable of degrading CPC's and HF resulting in copious biofilms [2]. The accepted procedure for removal of fungal biofilms during field operations is cleaning with isopropyl alcohol (IPA) [3]. The current study evaluated different cleaning procedures of multiple coating systems in terms of fungal biofilm removal.

Six different base coating systems were exposed to contaminant fluids (CPC and HF) and fungal inoculation: Chromate-inhibited primer; Non-chromate inhibited primer; Polyurethane topcoat, standard high-solids Type I, Class H; Extended weatherability polyurethane topcoat, Type IV, Class H; Hydrophobic coating, applied over Type I; Hydrophobic coating, applied over Type IV. The different coating systems were applied to aluminum 2024 panels, a common aircraft alloy. The operational fluids consisted of a common HF and CPC both with and without an added mildew inhibitor (fungistat).

Five fungal species - Aspergilus brasiliensis, Hormoconis resinae, Trichoderma virens, Aureobasidium pullulans, and Talaromyces pinophilus - were incorporated into a fungal spore suspension. The coated aluminum coupons were sprayed with the spore suspension using a spray atomizer and placed inside of an environmental chamber. The temperature of the chamber was held at $30^{\circ} \mathrm{C}$ with the relative humidity held at $95 \%$ for 84 days.

The effects of chemicals and processes used to remove and/or neutralize (sanitize) the biological growths and operational chemical residues were examined, with respect to the removal of growths as well as to control for the effect of cleaning procedures on results of the various analytical results on the underlying coating surfaces. Cleaning chemicals used included IPA, acetone (ACE), ethanol (EtOH), methanol $(\mathrm{MeOH})$, and commercially available cleanser (NavClean). Examinations of intact fungal mats were performed using scanning electron microscopy (SEM) and atomic force microscopy (AFM). Low $\mathrm{kV}$ SEM was used at $5 \mathrm{kV}$ accelerating voltage and $1 \mu \mathrm{A}$ beam current. The coupons were mounted atop a stub using carbon tape with no further modifications. Observations in AFM were carried out with intermittent "tapping" mode in ambient air, and the surface was investigated using commercially available silicon nitride $\left(\mathrm{Si}_{3} \mathrm{~N}_{4}\right)$ AFM tips.

Cleaning protocols were evaluated in their abilities to remove fungal hyphae and spores and additives. As the first step, IPA was used to clean a coupon containing Type IV topcoat-no additives, with fungal hyphae and spores seen visually and at higher magnification via SEM. Visual inspection indicated the 
fungal biofilm had been removed. However, inspection at higher magnification revealed the hyphae and a few spores persisted. Serial applications of IPA, ACE, EtOH and $\mathrm{MeOH}$ did not completely remove the fungal biofilm either. Only after application of NavClean followed by a distilled water $\left(\mathrm{dH}_{2} \mathrm{O}\right)$ rinse was the entire biofilm removed.

Primer-only (chromate primer and non-chromate primer) post-exposure coupons having fungal biofilms were cleaned using three separate cleaning methods: 1) IPA, 2) IPA $>\mathrm{ACE}>\mathrm{EtOH}>\mathrm{MeOH}$ and 3) NavClean $>\mathrm{dH}_{2} \mathrm{O}$. Separate areas were cleaned on each coupon using one of the cleaning methods. Regardless of cleaning method or primer type, fungal hyphae and spores were no longer visible at high magnification post-cleaning.

The effectiveness of the cleaning procedures was evaluated on coupons covered in CPC without fungistat with Type I and Type IV topcoats. Three separate areas on each coupon were chosen for cleaning with one of the cleaning methods. Regardless of topcoat type, fungal spores persisted in the CPC. The Type I topcoat with CPC after cleaning with IPA was evaluated (Figure 1). Prior to cleaning, segmented fungal hyphae can clearly be observed either on or within the CPC itself. After cleaning, trenches in the CPC where fungal hyphae were prior were observed. These results indicated that fungi grew within the CPC but did not adhere to the topcoat itself. In comparison, fungal growth on bare topcoat produced significantly more adherent hyphae that required NavClean for complete removal.

Various common cleaning solvents used on the fungal hyphae were shown to be relatively ineffective in removing the attached growths from the coating surfaces (IPA, ACE, EtOH and MeOH). The NavClean solution was the most effective in removing growths from organic coatings surfaces. Combinations of cleaning procedures may be required to remove both fungal growths and operational fluids which are acting as additional nutrients for microbiological propagation.

\section{References}

[1] DM Lavoie et al., "Microfungal degradation of polyurethane paint and corrosion of aluminum alloy in military helicopters," CORROSION / 97, Paper no. 218 (Houston, TX: NACE International, 1997), p. 7.

[2] RI Ray, BJ Little, ES Arafat, "A Laboratory Evaluation of Corrosion Preventive Compounds and Mildew Inhibitors in the Presence of Fungi," Report No. NRL/MR/7330--10-9273, Aug. 19, (Stennis Space Center, MS: Naval Research Laboratory, 2010).

[3] NAVAIR 01-1A-509-5 Technical Manual, Cleaning and Corrosion Control, Vol 1-5, March 2005.

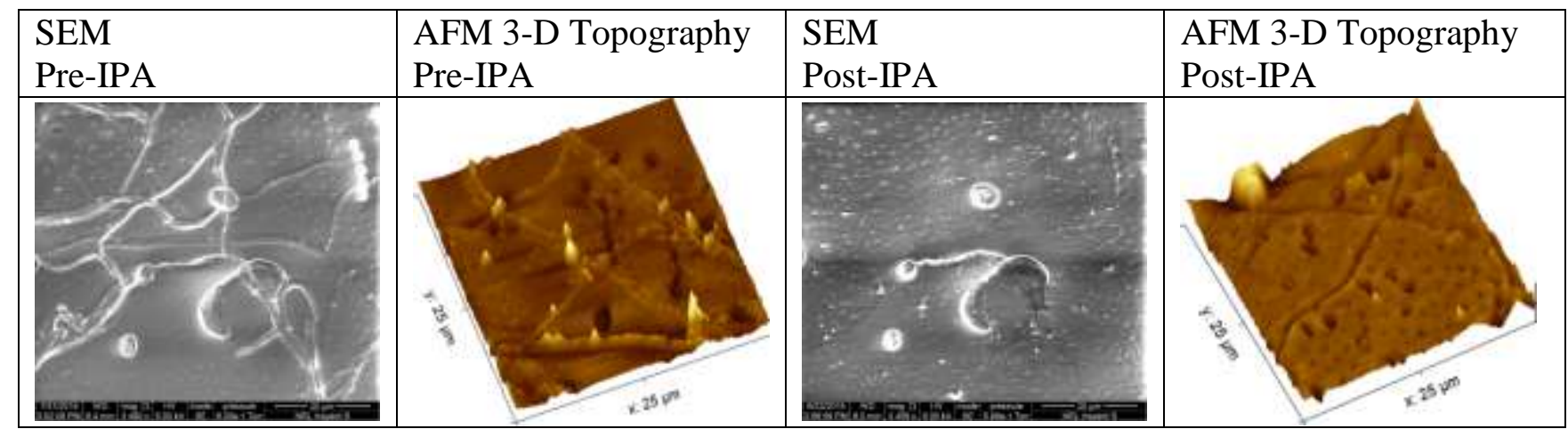

Figure 1. Scanning electron microscopy (SEM) and atomic force microscopy (AFM) images of Type I topcoat with CPC and fungal inoculation pre- and post-cleaning with iso-propyl alcohol (IPA). 